\title{
Current treatment approaches for breast cancer patients with HER2-positive disease in the adjuvant, and neo-adjuvant setting
}

\author{
Rashmi Purushottam Surti*
}

Maharashtra University of Health Sciences, Maharashtra, India

Received: 11 March 2021

Accepted: 06 April 2021

\section{*Correspondence:}

Dr. Rashmi Purushottam Surti,

Email: rashmisurti@gmail.com

Copyright: ( $)$ the author(s), publisher and licensee Medip Academy. This is an open-access article distributed under the terms of the Creative Commons Attribution Non-Commercial License, which permits unrestricted non-commercial use, distribution, and reproduction in any medium, provided the original work is properly cited.

\begin{abstract}
Breast cancer $(\mathrm{BC})$ is the second most common cancer and the leading cause of mortality among women globally. Approximately $20 \%$ to $25 \%$ of BC patients have amplification of the human epidermal growth factor receptor 2(HER2) genes, a marker of poor prognosis. However, the introduction of anti-HER2- therapies (trastuzumab, followed closely by lapatinib, pertuzumab, and T-DM 1) has changed the natural history of HER2-positive BC and improved the prognosis and survival in HER2-positive BC patients. The approval of trastuzumab and pertuzumab linked with a taxane as a first-line treatment and follow-up treatment with the antibody-drug conjugate T-DM1 has undeniably contributed to attaining these outcomes. The Tyrosine Kinase Inhibitor lapatinib is another commonly used treatment in combination with capecitabine, approved on the basis of an improvement in progression-free survival. The superiority of combination anti-HER2 therapy to achieve more complete inhibition of the various HER receptor dimers has been demonstrated in clinical studies. Nonetheless, studies have also suggested that some HER2-amplified tumors may benefit from anti-HER2 therapy combined with only a single chemotherapy agent or in the absence of any chemotherapy. However, despite therapeutic advances, tumors expressing estrogen receptor (ER) have poorer responses to targeted therapy and are more likely to relapse. A better understanding of resistance to existing anti-HER2 agents, along with the role played by the microenvironment and of interconnected signaling pathways, can permit tailor-made therapeutic options for each patient. The aim of this review is to evaluate treatment approaches for BC patients with HER2-positive disease in the adjuvant, and neoadjuvant setting.
\end{abstract}

Keywords: Breast cancer, HER2

\section{INTRODUCTION}

Cancer is the second leading cause of mortality worldwide and is estimated to be the cause of 9.6 million deaths in 2018. ${ }^{1}$ Breast cancer (BC) is the most commonly occurring cancer in women and the second most common cancer overall. $^{2}$ There were over 2 million new cases of $\mathrm{BC}$ in 2018 , with an estimate of 627,000 women due to this disease. ${ }^{3}$ In India, BC is ranked as the number one cancer among females, with the age-adjusted rate as high as 25.8 per 100,000 women and mortality 12.7 per 100,000 women. ${ }^{4}$
Breast cancer is a heterogeneous disease, with approximately $20 \%$ to $25 \%$ of patients having amplification of the human epidermal growth factor receptor 2 (HER2) genes. ${ }^{5}$ HER2 is a transmembrane protein with tyrosine kinase activity encoded by the ERBB2 gene. Ligand-dependent and independent signaling through HER2 results in cell proliferation and tumor growth. ${ }^{6}$ HER2 overexpression is associated with poor clinical prognosis, poorly differentiated, high-grade tumors reduced responses in younger patients to traditional therapies and decreased survival., ${ }^{7,8}$

However, the successful development of HER2-directed therapies in the past two decades, first in the palliative and 
then the curative-intent settings, BC-specific outcomes are now dramatically improved for affected women. ${ }^{9}$ A substantial number of HER2-targeted agents are available including monoclonal antibodies, small molecule inhibitors, and antibody-drug conjugates. ${ }^{10}$ The introduction of anti-HER2- therapies (trastuzumab, followed closely by lapatinib, pertuzumab, and T-DM1) has changed the natural history of HER2-positive BC and led to notable improvements in survival of both early and advanced settings. ${ }^{10-12}$
Neo-adjuvant treatment with a combination of sequential chemotherapy and HER2-targeted therapy, followed by breast surgery, radiotherapy (if indicated), completion of 12 months of HER2-directed therapy, and depending on the tumor biology, endocrine adjuvant therapy is currently the standard of care in HER2-positive early BC. ${ }^{13}$ This article will review current treatment approaches for $\mathrm{BC}$ patients with HER2-positive disease in the adjuvant, and neoadjuvant setting.

Table 1: Anti-HER2 blocking agents- mechanisms of action. ${ }^{16}$

\begin{tabular}{|c|c|c|}
\hline Class of compounds & Agent (S) & Mechanism of action \\
\hline \multirow[t]{2}{*}{ Monoclonal antibody } & Trastuzumab & $\begin{array}{l}\text { Prevent formation of HER2-containing heterodimers, } \\
\text { antibody-dependent cell-mediated cytotoxicity (ADCC), } \\
\text { disruption of downstream signaling pathways, inhibition } \\
\text { of cleavage of HER } 2 \text {, and promoting endocytosis of } \\
\text { HER } 2 \text { receptor. }\end{array}$ \\
\hline & Pertuzumab & $\begin{array}{l}\text { It exerts its function by binding with an epitope on the } \\
\text { extracellular domain of HER } 2 \text { receptors, therefore } \\
\text { preventing the formation of HER2-containing } \\
\text { heterodimers. }\end{array}$ \\
\hline Antibody-drug conjugates & Trastuzumab-DM1 & $\begin{array}{l}\text { Trastuzumab's action } \\
\text { Selective delivery of the antimicrotubule agent DM1 }\end{array}$ \\
\hline \multirow[t]{2}{*}{ Small-molecule inhibitors } & Lapatinib & $\begin{array}{l}\text { Reversible and dual small molecular inhibitor of HER2 } \\
\text { and HER1 with prolonged inhibition of tyrosine } \\
\text { phosphorylation in tumor cells. }\end{array}$ \\
\hline & Afatinib, neratinib & Irreversible dual inhibitor of EGFR and HER2 \\
\hline
\end{tabular}
growth factor receptor.

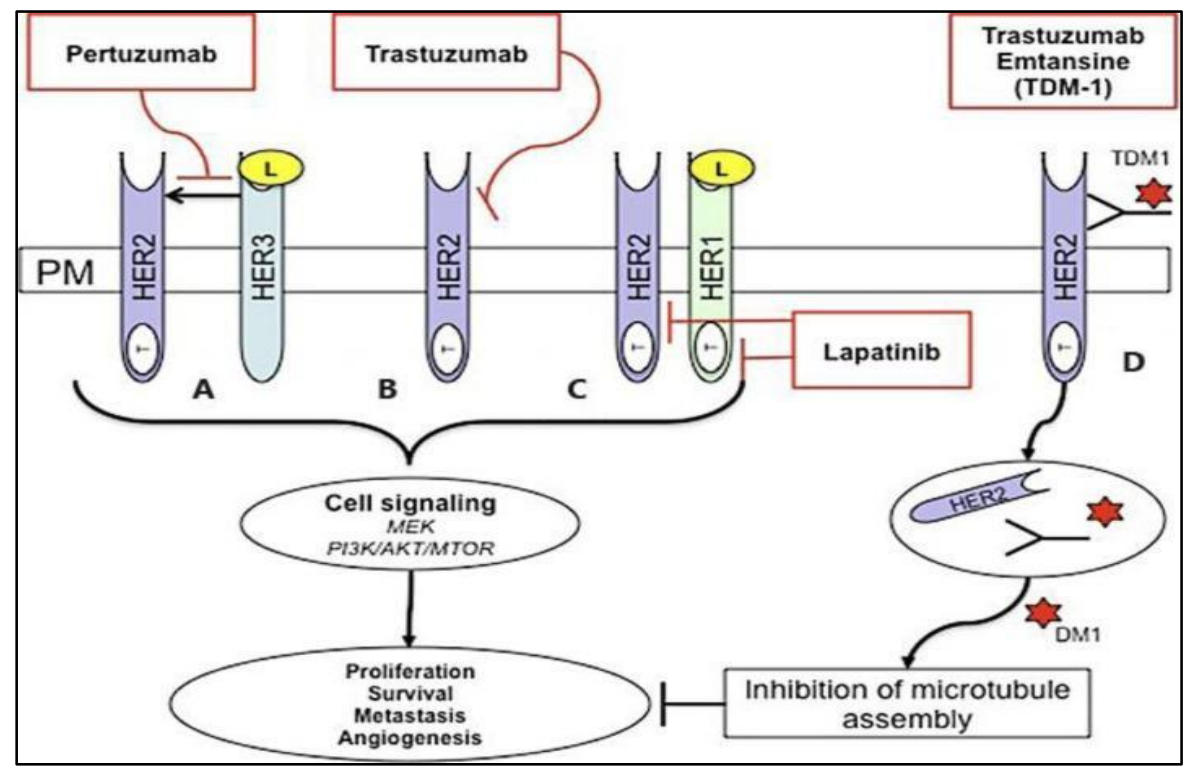

Figure 1: HER2 Targeted therapies for the treatment of metastatic BC. ${ }^{14}$

\section{The function of human epidermal growth factor receptors and their inhibitors}

The human epidermal growth factor (EGF), HER1, HER2, HER3, and HER4 are receptor tyrosine kinases within the plasma membrane (PM). These factors are involved in signal transduction pathways that modulate cellular processes. $^{14}$ All factors except HER3 consist of an extracellular ligand-binding domain and intracellular tyrosine kinase domain $(\mathrm{T})$. The ligand (L) binds the receptor's extracellular domain, homo-dimerization, and hetero-dimerization leads to tyrosine kinase domain 
phosphorylation and activation of downstream signalling pathways. ${ }^{14}$ There is an emergence of several novel HER2targeting agents, including the monoclonal antibody trastuzumab and pertuzumab, the antibody-drug conjugate trastuzumab emtansine (also known as T-DM1), and the tyrosine kinase inhibitors (TKIs) lapatinib and neratinib, which target the signal transduction pathway downstream from HER 2 (Figure 1 and Table 1). 8,15,16

\section{HER2-INHIBITORS}

Trastuzumab is a humanized monoclonal antibody. It is the first HER2-targeting drug introduced to BC clinics and remains a key component of the most effective regimens used to treat HER2-positive BC now. Pertuzumab is an alternative monoclonal anti-HER2 antibody. It binds HER2 at a different location than trastuzumab. It prevents the formation of HER2-HER3 heterodimers. ${ }^{15}$ Lapatinib is a reversible small-molecule TKIs which has dual activity against the tyrosine kinase ATP-binding pocket of HER 1 and HER2.

Trastuzumab-emtansine (T-DM1) is an antibody-drug conjugate (ADC). This new drug allows for targeted delivery of cytotoxic molecules to the tumor, thereby increasing efficiency and reducing toxicity at the same time. ${ }^{15}$

\section{HER2-INHIBITORS AND TUMOR RESISTANCE}

Although BC will be cured in some patients treated in the adjuvant setting, it is predicted that a fraction will eventually recur. Tumors harbor de novo or acquire resistance to therapeutic inhibitors of HER2. ${ }^{17,18}$ General mechanisms of resistance to HER2-targeted therapies that occur at three levels. The first comprises mechanisms intrinsic to the target, such as molecular changes in the target receptor; the expression of p95HER2, which is a truncated HER2 receptor; and HER2 gene amplification. ${ }^{19}$ Secondly, resistance involving parallel signaling pathways bypassing HER2 inhibition, such as increased activation of HER3, aberrant activation of pathways downstream of the receptor, and compensatory crosstalk with other pathways, can also occur. ${ }^{19}$ The third mechanism includes resistance due to defects in the apoptosis pathway in tumor cells or in extrinsic host factors participating in the action of the drugs. ${ }^{19}$

\section{BIOLOGICAL INSIGHTS INTO IMPROVED HER2 TARGETING}

\section{Inhibition of HER family dimerization}

A known mechanism of resistance to anti-HER2 therapy is the dimerization of HER family members. ${ }^{20}$ All members of the HER family can form dimers together, nevertheless, HER2 and HER3 form a mainly potent heterodimer that is important in BC development and growth. Though HER3 does not exert tyrosine kinase activity on its own, dimerization with HER2 drastically increases downstream signaling activity and provides a mechanism of escape from HER2 inhibition. ${ }^{21-24}$ Pertuzumab is a humanized monoclonal antibody that binds to the dimerization domain of HER2. It is an inhibitor of HER2/HER3 dimerization and also induces antibody-dependent cellular cytotoxicity (ADCC). While pertuzumab has some clinical activity of its own, when used along with trastuzumab, the dual binding to HER2 leads to synergistic action. ${ }^{8}$

In the Phase III Clinical Evaluation of Pertuzumab and Trastuzumab (CLEOPATRA) study, 808 patients with metastatic BC who had not previously received anti-HER2 therapy for metastatic disease, were treated with the combination of pertuzumab and trastuzumab with docetaxel. Median progression-free survival (PFS) as assessed by investigators improved by 6 months (HR 0.65 , $\mathrm{p}<0.001)$ and there was a $10.8 \%$ improvement in objective response rate. ${ }^{25}$ The combination also leads to a marked improvement in overall survival (OS) by almost 16 months compared to standard trastuzumab plus docetaxel (HR $0.68, \mathrm{p}<0.001) .{ }^{26}$ Ever since this study, pertuzumab plus trastuzumab has replaced trastuzumab as the standard of care for first-line metastatic BC.

Recently, several TKIs like, lapatinib and neratinib have been developed that target the signal transduction pathway downstream from HER2. In both early and metastatic BC, it is effective against HER2 amplification when given in combination with trastuzumab. ${ }^{27,28}$ But, in preclinical studies, most HER2 somatic mutations were resistant to lapatinib. ${ }^{29}$ One more HER2-targeting TKI, neratinib has emerged as a potent inhibitor of HER2 activity. It is an irreversible pan-inhibitor of HER2 and HER1/EGFR and has been found to be more effective than lapatinib in blocking HER2 activation. ${ }^{30,31}$

\section{OPTIMIZING HER2-TARGETED THERAPY FOR BREAST CANCER}

The development of HER2-targeted therapies has revolutionized the management of women with HER2positive BC. These targeted therapies have significantly improved their outcomes (Table 1). ${ }^{8,15,16}$

With the success of anti-HER2 therapy in MBC, trastuzumab was evaluated in the adjuvant setting in a series of pivotal trials. Major international studies of adjuvant trastuzumab with a planned enrollment of $>13,000$ women with HER-2-positive EBC were: the Herceptin ${ }^{\circledR}$ Adjuvant (HERA) trial, the National Surgical Adjuvant Breast, and Bowel Project (NSABP) B-31 trial, the North Central Cancer Treatment Group (NCCTG) N9831 trial and the Breast Cancer International Research Group (BCIRG) 006 trial. At a 1-year median follow-up, patients treated with trastuzumab in the HERA trial experienced a $46 \%$ lower risk of a first event (hazard ratio [HR], 0.54; 95\% confidence interval [CI], 0.43-0.67; $\mathrm{p}<0.0001)$ than patients under observation. This corresponded to an absolute DFS benefit favoring trastuzumab of $8.4 \%$ at 2 years. ${ }^{32}$ 


\section{CURRENT STANDARDS IN HER2-POSITIVE EARLY BREAST CANCER}

For HER2-positive early BC, the current standard of care includes trastuzumab (with or without pertuzumab) and chemotherapy, given either before or after surgery. This is based on results from several clinical trials which demonstrated a significant benefit of trastuzumab in standards of care in both the adjuvant and neoadjuvant settings. ${ }^{32-35}$ In the phase III Herceptin Adjuvant (HERA) trial, 1 year of adjuvant trastuzumab was associated with significant improvements in both 10 -year rates of diseasefree survival (DFS; 69\% versus 63\%; HR 0.76) and 12year rates of OS (79\% versus $73 \%$; HR 0.74$)$ compared to observation. $^{32,33}$

In the phase III Neo-adjuvant Herceptin (NOAH) trial, HER2-positive patients treated with trastuzumab plus chemotherapy had a significantly higher rate of pathologic complete response ( $\mathrm{pCR}$ ) than patients who only received chemotherapy $(38.5 \%$ versus $19.5 \%$; HR $0.29, p=0.0135)$ and these patients remained disease-free longer (5-year event-free survival [EFS] $58 \%$ versus $43 \%$; HR 0.64 , $\mathrm{p}=0.016) .{ }^{35}$ Even though trastuzumab has demonstrated efficacy in early $\mathrm{BC}$, a significant proportion of patients will eventually progress. In the HERA trial, after 10 years of follow up, $28.8 \%$ of patients treated with trastuzumab experienced disease progression. Likewise, in the NOAH trial, at only 5 years post-treatment with trastuzumab, $42 \%$ of patients treated, experienced a disease recurrence. ${ }^{35}$ Thus, clearly, for many patients with HER2-positive BC, there is still a significant unmet need, and research in recent years has focused on identifying novel approaches to adjuvant and neoadjuvant therapy that can improve outcomes for these patients.

\section{Novel approaches to HER2-targeted adjuvant therapy}

Many novel HER2-targeting agents have been studied including dual HER 2 blockade. These agents are potential adjuvant therapy for patients with HER2-positive BC.

\section{Lapatinib}

Lapatinib has been evaluated as a potential adjuvant therapy for HER2-positive BC, either alone or in combination with trastuzumab. In the Tykerb Evaluation after Chemotherapy (TEACH) trial, lapatinib was compared to placebo in women with HER2-positive early BC. Women had previously received adjuvant chemotherapy but not trastuzumab. The study found that single-agent lapatinib failed to demonstrate a significant DFS benefit over placebo (HR 0.83, 95\% CI 0.70-1.00). It was found that there was a marginal benefit for patients with HER2-positive disease confirmed by central fluorescence in situ hybridization. ${ }^{36}$ In the Adjuvant Lapatinib and/or Trastuzumab Treatment Optimisation (ALTTO) trial, patients who received single-agent lapatinib had poorer outcomes compared to patients who received trastuzumab (HR 1.34). ${ }^{37}$ Lapatinib and trastuzumab combination appeared to improve outcomes, as patients who received both lapatinib and trastuzumab, either in combination $(\mathrm{L}+\mathrm{T})$ or in sequence $(\mathrm{T} \rightarrow \mathrm{L})$, showed significant DFS rates ( $\mathrm{L}+\mathrm{T}: 88 \%$ and $\mathrm{T} \rightarrow \mathrm{L}: 87 \%$ ) compared to patients who received single-agent (lapatinib L: $82 \%$ ). However, at the 5 years of follow-up, the combination did not sufficiently improve either DFS or OS compared to single-agent trastuzumab. ${ }^{38}$ At present, lapatinib is not being further investigated in the adjuvant setting, either alone or in combination with trastuzumab.

\section{Neratinib}

Studies of neratinib in the adjuvant setting have been promising. Phase III study, Neratinib after trastuzumabbased adjuvant therapy in HER2-positive BC (ExteNET) compared neratinib ( $240 \mathrm{mg}$ daily) to placebo. ${ }^{39}$ This was multicenter, randomized, double-blind, placebocontrolled, conducted at 495 centers in Europe, Asia, Australia, New Zealand, and North and South America. Women included in the study were with stage I-III HER2positive $\mathrm{BC}$, who had completed neoadjuvant and adjuvant trastuzumab up to 2 years (amended to 1 year) before randomization. Patients with stage I-III node-positive and node-negative patients with tumors greater than $1 \mathrm{~cm}$ in size were included. In this study, neratinib improved invasive DFS by 2 years by $2.3 \%$ over placebo (HR 0.67 , $\mathrm{p}=0.009) .{ }^{39}$

This improvement was most discrete in patients with hormone receptor (HR)-positive tumors (HR 0.51, $\mathrm{p}=0.001)$. This study results suggested that neratinib might provide an additional treatment option for this subset of patients who have an ongoing, long-term, and fairly constant risk of relapse on trastuzumab. Also at a 5-years follow-up, the benefit with neratinib was maintained with a $2.5 \%$ absolute improvement in invasive DFS $(90.2 \%$ versus $87.7 \%$; $\mathrm{HR} 0.73, \mathrm{p}=0.008$ ) for the whole population. ${ }^{40}$ This improvement in invasive DFS was most apparent in HR-positive patients $(91.2 \%$ versus $86.8 \%$; HR $0.60, p=0.002) .{ }^{40}$ It was observed that patients who have completed adjuvant trastuzumab less than 1 year prior to the start of the study showed the maximum benefit with neratinib. ${ }^{40}$

\section{Pertuzumab}

Pertuzumab in addition to chemotherapy and trastuzumab as adjuvant therapy in participants with HER2-positive primary BC, (APHINITY) study examined the pertuzumab (P) and trastuzumab (T) combination as adjuvant treatment, compared to standard trastuzumab plus chemotherapy $(\mathrm{C})$ in 4805 patients with HER2positive early BC. ${ }^{41}$ Study included patients who had either node-positive disease or node-negative disease (pN0) and a tumor size of $>1.0 \mathrm{~cm}$. Patients with pNO, T1b tumors with high-risk features were initially eligible. 4805 patients were randomized to $\mathrm{C}$ and $\mathrm{T}$ plus either $\mathrm{P}$ $(\mathrm{n}=2400)$ or Pla $(\mathrm{n}=2405) .{ }^{41}$ 
This study met its primary endpoint of improved invasive DFS at 3 years $(94.1 \%$ versus $93.2 \%$; HR $0.81, \mathrm{p}=0.045)$, the magnitude of the benefit was modest and there was no associated improvement in OS $(97.7 \%$ in both groups; HR $0.89, \mathrm{p}=0.467)$. Subgroup analysis suggested a somewhat greater effect on ER-negative tumors (HR 0.76, $\mathrm{P}=0.085$ ). Pertuzumab treatment was associated with an increase in grade $\geq 3$ diarrhea $(9.8 \%$ versus $3.7 \%) .{ }^{41}$ Results from key phase III trials are summarized in Table 2.

Table 2: Disease-free survival and overall survival rates for phase III adjuvant trials of novel HER2 inhibitors. ${ }^{8}$

\begin{tabular}{|c|c|c|c|c|c|c|}
\hline Agent/trial & Disease setting & Regimen & $\mathbf{N}$ & $\begin{array}{l}\text { Follow- } \\
\text { up }\end{array}$ & DFS & OS \\
\hline \multicolumn{7}{|l|}{ Lapatinib } \\
\hline $\begin{array}{l}\text { Adjuvant Lapatinib } \\
\text { And/Or } \\
\text { Trastuzumab } \\
\text { Treatment } \\
\text { Optimisation } \\
\text { (ALTTO) trial }\end{array}$ & \multirow{3}{*}{$\begin{array}{l}\text { Stage I-III } \\
\text { adjuvant } \\
\text { therapy }\end{array}$} & $\begin{array}{l}\text { Lapatinib } \\
\text { trastuzumab+ }\end{array}$ & 8381 & 6 years & $85 \%$ (HR 0.86) & $93 \%$ (HR 0.86) \\
\hline $\begin{array}{l}\text { Piccart-Gebhart et } \\
\mathrm{al}^{37}\end{array}$ & & $\begin{array}{l}\text { - Lapatinib (34 } \\
\text { w) } \rightarrow \\
\text { Trastuzumab (12 } \\
\text { w) }\end{array}$ & & & $84 \%$ (HR 0.93) & $92 \%$ (HR 0.88) \\
\hline $\begin{array}{l}\text { Moreno-Aspitia et } \\
\mathrm{al}^{38}\end{array}$ & & $\begin{array}{l}\text { - Trastuzumab } \\
\text { - Lapatinib }\end{array}$ & & & $\begin{array}{l}82 \% \\
82 \% \text { (HR 1.34) }\end{array}$ & $\begin{array}{l}91 \% \\
93 \% \text { (HR 1.36) }\end{array}$ \\
\hline $\begin{array}{l}\text { TEACH } \\
\text { Goss et } \mathrm{al}^{36}\end{array}$ & $\begin{array}{l}\text { Stage I-III } \\
\text { delayed } \\
\text { adjuvant } \\
\text { therapy. Prior } \\
\text { trastuzumab } \\
\text { unless } \\
\text { contraindicated }\end{array}$ & $\begin{array}{l}\text { - Lapatinib } \\
\text { - Placebo }\end{array}$ & 3147 & $\begin{array}{l}47.4 \mathrm{mo} \\
48.3 \mathrm{mo}\end{array}$ & $\begin{array}{l}87 \% \text { (HR 0.83) } \\
83 \%\end{array}$ & $\begin{array}{l}94 \% \text { (HR 0.99) } \\
94 \%\end{array}$ \\
\hline \multicolumn{7}{|l|}{ Neratinib } \\
\hline $\begin{array}{l}\text { ExteNET } \\
\left(\text { Martin et } \mathrm{al}^{40}\right.\end{array}$ & $\begin{array}{l}\text { Stage I-III } \\
\text { delayed } \\
\text { adjuvant } \\
\text { therapy. Prior } \\
\text { trastuzumab }\end{array}$ & $\begin{array}{l}\text { - Neratinib } \\
\text { - Placebo }\end{array}$ & 2840 & 5 years & $\begin{array}{l}90.2 \%(\mathrm{HR} \\
0.73) * \\
87.7 \% *\end{array}$ & Not mature \\
\hline \multicolumn{7}{|l|}{ Pertuzumab } \\
\hline $\begin{array}{l}\text { APHINITY } \\
\text { Von Minckwitz et } \\
\mathrm{al}^{41}\end{array}$ & $\begin{array}{l}\text { Stage II-III } \\
\text { adjuvant } \\
\text { therapy }\end{array}$ & $\begin{array}{l}\text { - Pertuzumab } \\
\text { (plus chemo and } \\
\text { trastuzumab) } \\
\text { - Placebo (plus } \\
\text { chemo and } \\
\text { trastuzumab) }\end{array}$ & 4805 & $36 \mathrm{mo}$ & $\begin{array}{l}94.1 \%(\mathrm{HR} \\
0.81)^{*} \\
93.2 \% *\end{array}$ & $\begin{array}{l}97.7 \%(\mathrm{HR} \\
0.89) \\
97.7 \%\end{array}$ \\
\hline
\end{tabular}

Chemo, chemotherapy; DFS, disease-free survival; ET, endocrine therapy; mo, months; OS, overall survival, invasive DFS.

\section{Ado-trastuzumab emtansine (T-DM1)}

Ado-trastuzumab emtansine (T-DM1) is an immunoconjugate of trastuzumab with an effective microtubule inhibitor agent. It is a derivative of fungal toxin emtansine (DM1) which has three capabilities; antiHER2 function of trastuzumab, DM1 induced cytotoxicity, and tissue-specific expression. ${ }^{42}$

The KATHERINE trial compared adjuvant therapy with T-DM1 to adjuvant trastuzumab in patients with HER2positive early $\mathrm{BC}$ who had residual disease following neoadjuvant therapy including a minimum of six cycles of taxane-based chemotherapy and nine weeks trastuzumab. ${ }^{42}$ Patients were randomized to either 14 cycles of ado-trastuzumab emtansine versus 14 cycles of trastuzumab. Treatment with 14 cycles of adjuvant T-DM1 resulted in a significant improvement in rates of invasive disease-free survival (iDFS) compared to adjuvant trastuzumab. ${ }^{43}$

iDFS favored T-DM1 in all prespecified patient subgroups. At 3 years, a greater proportion of patients receiving T-DM1 remained free of distant recurrence (89.7\% versus $83.0 \%$; HR 0.60). There was a trend towards improved overall survival (OS) in patients receiving T-DM1. The study concluded that adjuvant $\mathrm{T}$ DM1 demonstrated both statistically significant and 
clinically meaningful improvements in iDFS compared to trastuzumab in patients with invasive residual after neoadjuvant therapy. ${ }^{43}$

\section{Neoadjuvant therapy for HER2-positive breast cancer}

Trastuzumab as neoadjuvant therapy provides significant clinical benefits and reduces the rate of distant metastasis. $^{44}$ Clinical studies have revealed that trastuzumab-based neoadjuvant therapy has a higher pCR (termed as the absence of residual cancer in the breast or axillary lymph node pathology) in the treatment of HER2positive $\mathrm{BC}^{45}$

At first, a small randomized trial was conducted to determine whether the addition of trastuzumab to chemotherapy in the neoadjuvant setting could increase (pCR) rate in patients with HER2 positive disease. This study confirmed the role of trastuzumab in the neoadjuvant scenario. ${ }^{46}$ Another multicenter, open-label, randomized phase III study was NOAH trial. ${ }^{47}$ After a median followup of 5.4 years, neoadjuvant treatment with trastuzumab improved the 5-year DFS rate as $58 \%$ to $43 \%(\mathrm{p}<0.001)$, with an unadjusted HR of 0.64 . A strong association with pCR was observed in patients given trastuzumab, improving the pCR from 22 to $43 \%(\mathrm{p}<0.001){ }^{35}$
In Taxol Epirubicin Cyclophosphamide Herceptin Neoadjuvant (TECHNO) trial, 217 HER2-positive patients with larger tumors $(\geq 2 \mathrm{~cm})$, received four cycles of $\mathrm{AC}$ (epirubicin and cyclophosphamide, EC), followed by four cycles of TH (paclitaxel and trastuzumab) as neoadjuvant treatment. Pathologic complete response was obtained in nearly $38.7 \%$. 3-year DFS (88\% versus $71 \%$; $\mathrm{p}=0.003)$ and OS $(96 \%$ versus $85 \%$; $\mathrm{p}=0.007)$ was improved..$^{48}$

Other trials, such as the American Z1041 trial, Quattro study, and Hanna trial, also enrolled HER2 positive BC patients with comparable inclusion criteria as TECHNO. ${ }^{49-}$ 51 These trials also evaluated treatment with chemotherapy plus trastuzumab as concurrently or consequence regimens (Table 3).

\section{Other therapy in the neoadjuvant setting}

The GeparQuinto phase III trial compared the efficacy of two HER2-targeted drugs, lapatinib and trastuzumab, with the combination of four cycles of chemotherapy with EC, followed by docetaxel. ${ }^{52}$ The study results confirmed that the trastuzumab arm showed $\sim 7 \%$ more pCR than lapatinib $\operatorname{arm}(30.3 \%$ versus $22.7 \%$; $=0.04) .^{52}$

Table 3: Optimal clinical trials in the neoadjuvant setting for HER2-positive breast cancer. ${ }^{57}$

\begin{tabular}{|c|c|c|c|c|c|}
\hline $\begin{array}{l}\text { Drug or study } \\
\text { name }\end{array}$ & $\begin{array}{l}\text { Neoadjuvant } \\
\text { chemotherapy }\end{array}$ & $\begin{array}{l}\text { No. of } \\
\text { patients }\end{array}$ & $\begin{array}{l}\text { Pathological } \\
\text { complete } \\
\text { response }(\%)\end{array}$ & Comments & Reference \\
\hline $\begin{array}{l}\text { The NSABP B- } \\
41 \text { trial }\end{array}$ & $\begin{array}{l}\mathrm{AC} \rightarrow \mathrm{TH} \text { or } \mathrm{TL} \text { or } \\
\mathrm{THL}\end{array}$ & $\begin{array}{l}181 \text { versus } \\
174 \text { versus } \\
174\end{array}$ & $\begin{array}{l}52.5 \% \text { versus } \\
53.2 \% \text { versus } \\
62.0 \%\end{array}$ & $\begin{array}{l}\mathrm{H}+\mathrm{L} \text { no better. } \\
\text { All patients } \\
\text { received } \\
\text { anthracyclines }\end{array}$ & $\begin{array}{l}\text { Robidoux et } \\
\mathrm{al}^{53}\end{array}$ \\
\hline $\begin{array}{l}\text { Pertuzumab } \\
\text { The NeoSphere } \\
\text { trial }\end{array}$ & $\begin{array}{l}\mathrm{Do}+\mathrm{H} \text { vs } \mathrm{Do}+\mathrm{P}+\mathrm{H} \\
\text { vs } \mathrm{Do}+\mathrm{P} \text { vs } \mathrm{P}+\mathrm{H}\end{array}$ & $\begin{array}{l}107 \text { versus } \\
107 \text { versus } \\
107 \text { versus } \\
96\end{array}$ & $\begin{array}{l}29.0 \% \text { versus } \\
45.8 \% \text { versus } \\
24.0 \% \text { versus } \\
16.8 \%\end{array}$ & $\begin{array}{l}\geq \mathrm{T} 2 \text {; Combination } \\
\mathrm{P}+\mathrm{H} \text { result in } \\
\text { better pCR }\end{array}$ & Gianni et al ${ }^{54,55}$ \\
\hline $\begin{array}{l}\text { The } \\
\text { TRYPHAENA } \\
\text { trial }\end{array}$ & $\begin{array}{l}\mathrm{FEC}+\mathrm{HP} \rightarrow \\
\mathrm{Do}+\mathrm{HP} \text { vs FEC } \rightarrow \\
\mathrm{Do}+\mathrm{HP} \text { vs TCHP }\end{array}$ & $\begin{array}{l}223 \text { patients } \\
\text { in total }\end{array}$ & $\begin{array}{l}62 \% \text { versus } 57 \% \\
\text { versus } 66 \%\end{array}$ & $\begin{array}{l}\mathrm{TCH}+\mathrm{P} \text { is an } \\
\text { active combination }\end{array}$ & $\begin{array}{l}\text { Schneeweiss et } \\
\mathrm{al}^{56}\end{array}$ \\
\hline
\end{tabular}

T paclitaxel; F 5FU, E epirubicin, C cyclophosphamide, A adriamycin, M methotrexate, Do docetaxel, TC docetaxel plus carboplatin, H trastuzumab, $\mathrm{P}$ pertuzumab, L lapatinib, T-DM1 trastuzumab-maytansine.

The Lapatinib with trastuzumab for HER2-positive early BC (NeoALTTO) trial, an international, randomized, open-label, multicenter, phase III study, compared the efficacy of lapatinib or trastuzumab monotherapy, or the concomitant lapatinib and trastuzumab regimen, in addition to paclitaxel, in the neoadjuvant setting. ${ }^{27}$ In the combination arm, prominent progress on pCR of $51 \%$, was observed which is almost twice as much as the other two monotherapies against HER $2(29.5 \%$ in trastuzumab alone and $24.7 \%$ in lapatinib alone, $\mathrm{p}<0.001) .{ }^{27}$ Other studies with the dual inhibitory regimen, NSABP B-41 study, NeoSphere trial and the TRYPHAENA trial details are illustrated in Table 3. ${ }^{53-56}$

\section{NOVEL STRATEGIES TO OVERCOME RESISTANCE TO HER2-TARGETED THERAPY}

\section{Replacement of current anti-HER2 therapies for improved anti-HER2 drugs}

\section{$A D C s$}

ADCs offer a wider therapeutic window by more efficient and specific drug delivery. To improve tumor selectivity and reduce damage to normal cells, ADCs exploit target selectivity of monoclonal antibodies (MAbs) to deliver 
cytotoxic drugs to antigen-expressing cells. ${ }^{57}$ Several antiHER2 ADCs in clinical development are listed in Table 4.

\section{Novel TKIs}

There are, several novel TKIs in clinical development listed in Table 5.

\section{Escalating or de-escalating adjuvant therapy in HER2+ breast cancer}

Recently many studies have investigated modifications of the schedule of treatment with trastuzumab by either making it shorter and less toxic (de-escalation), or more effective with dual HER2 inhibition or extended treatment duration (escalation). ${ }^{63}$

Seven randomized trials investigated whether a shorter regimen of adjuvant trastuzumab may be as effective as 1year of trastuzumab, but with fewer side-effects. In four trials trastuzumab was given concomitantly with chemotherapy in the experimental arm with the aim to investigate drug synergism (FinHer, E2198, SOLD, and Short-HER trials), and three trials compared 6-month to the 12-month duration of trastuzumab (the Hellenic trial, PHARE, and PERSEPHONE).
In the FinHerstudy, 1010 women with axillary nodepositive or high-risk node-negative $\mathrm{BC}$ were randomized to receive 3 cycles of docetaxel or vinorelbine, followed in both groups by 3 cycles of fluorouracil $(F)$, epirubicin $(E)$, and cyclophosphamide (C) ${ }^{64} 232$ patients with HER 2 positive $\mathrm{BC}$ were further treated with trastuzumab or no additional therapy. Even with the shorter duration of trastuzumab after a median follow-up of 8 years, distant DFS $(83.3 \%$ versus $73 \%)$ and OS $(91.3 \%$ versus $82.3 \%)$ favored the trastuzumab arm. ${ }^{64}$

In the SOLD trial, 2,176 patients with early-stage HER2positive BC were randomized (1:1) to the 9-week trastuzumab arm or the 12-month trastuzumab arm. ${ }^{65}$ Patients in both arms received three cycles of docetaxel (80 $\mathrm{mg} / \mathrm{m} 2$ or $100 \mathrm{mg} / \mathrm{m} 2$ ) and trastuzumab three times a week, followed by three cycles of chemotherapy. ${ }^{65}$ Patients in the 9-week arm received no further treatment, whereas those in the 12-month arm received trastuzumab every 3 weeks for 14 cycles. The trial failed to establish that 9 weeks of adjuvant trastuzumab were not inferior to the standard 12 months in terms of DFS. ${ }^{65}$ The shorter trastuzumab treatment was safer to the heart than the longer treatment. In the 9-week group, there were 22 protocol-defined cardiac adverse events compared with 42 in patients receiving 1 year of trastuzumab $(\mathrm{p}=0.012){ }^{65}$

Table 4: HER2-directed ADCs in clinical development.

\begin{tabular}{|c|c|c|c|c|c|c|}
\hline Agent & $\begin{array}{l}\text { Anti-HER2 } \\
\text { MAb/payload } \\
\text { (target) }\end{array}$ & $\begin{array}{l}\text { Drug to } \\
\text { antibody } \\
\text { ratio }\end{array}$ & $\begin{array}{l}\text { Linker } \\
\text { drug }\end{array}$ & $\begin{array}{l}\text { Phase of } \\
\text { development }\end{array}$ & $\begin{array}{l}\text { ORR in } \\
\text { HER2- } \\
\text { positive }\end{array}$ & $\begin{array}{l}\text { ORR in } \\
\text { HER2 low } \\
\text { (IHC1+/2+/I } \\
\text { SH-) }\end{array}$ \\
\hline $\begin{array}{l}\text { Trastuzumab- } \\
\text { DM1 (T-DM1) }\end{array}$ & $\begin{array}{l}\text { Trastuzumab/ } \\
\text { DM1 (anti- } \\
\text { tubulin) }\end{array}$ & 3.5 & $\begin{array}{l}\text { Non- } \\
\text { cleavable }\end{array}$ & $\begin{array}{l}\text { US FDA } \\
\text { Approved }\end{array}$ & $43.6 \%$ & - \\
\hline $\begin{array}{l}\text { Trastuzumab } \\
\text { duruxtecan (DS- } \\
\text { 8201a) }\end{array}$ & $\begin{array}{l}\text { Trastuzumab/ } \\
\text { exatecan } \\
\text { derivative } \\
\text { (topoisomerase I } \\
\text { inhibitor) }\end{array}$ & 8 & Cleavable & $\begin{array}{l}\text { II/III } \\
\text { NCT03248492 } \\
\text { NCT03529110 } \\
\text { NCT03523585 }\end{array}$ & $54.5 \%$ & $50 \%$ \\
\hline SYD985 ${ }^{60}$ & $\begin{array}{l}\text { Duocarmycin } \\
\text { derivative } \\
\text { (alkylating agent) }\end{array}$ & 2.8 & Cleavable & $\begin{array}{l}\text { III } \\
\text { NCT03262935 }\end{array}$ & $33 \%$ & $\begin{array}{l}\mathrm{HR}+27 \% \\
\mathrm{HR}-40 \%\end{array}$ \\
\hline XMT-1522 & $\begin{array}{l}\text { XMT-1519/ } \\
\text { monomethyl } \\
\text { auristatin (anti- } \\
\text { tubulin) }\end{array}$ & 12 & Cleavable & $\begin{array}{l}\text { I } \\
\text { NCT02952729 }\end{array}$ & Unknown & Unknown \\
\hline
\end{tabular}

ADC, antibody-drug conjugate; HR+, hormone receptor-positive; HR-, hormone receptor-negative; IHC, immunohistochemistry; ISH, In Situ Hybridization; MAb, monoclonal antibody; NCT, ClinicalTrials.gov identifier; ORR, overall response rate; US FDA, United States Food and Drug Administration.

In the Short-HER study patients were randomly selected to receive 1 year of trastuzumab plus chemotherapy ("long" group) or 9 weeks of trastuzumab plus chemotherapy ("short" group). 66,67
The primary endpoints were DFS and OS. Secondary endpoints included failure rate at 2 years and the incidence of cardiac events. ${ }^{66,67}$ The 5-year DFS was not non-inferior $(87.5 \%$ versus $85.4 \%$ in the long and short groups, respectively, hazard ratio [HR] $1.15,90 \% \mathrm{CI}[0.91,1.46])$. 
In an analysis of DFS in patients with the earlier-stage disease (stage I and II) as compared to those with locally advanced disease (stage III), the shorter duration was not inferior to the longer one. There was no difference in OS at 5 years. ${ }^{66}$

Table 5: New anti HER 2 agents and combinations. ${ }^{62}$

\section{Novel HER2 antibodies}

\begin{tabular}{|c|c|}
\hline Agent & Mechanism of action \\
\hline $\begin{array}{l}\text { Margetuxim } \\
\text { ab } \\
\text { (MGAH22) }\end{array}$ & $\begin{array}{l}\text { Optimized Fc domain for enhanced } \\
\text { binding tothe activating low-affinity } \\
\text { Fc receptor, Fc } \gamma \text { RIIIA }\end{array}$ \\
\hline MCLA-128 & $\begin{array}{l}\text { IgG1 bispecific antibody with } \\
\text { enhanced ADCCactivity targeting } \\
\text { both HER2 and HER3receptors }\end{array}$ \\
\hline ZW-25 & $\begin{array}{l}\text { The bispecific antibody directed } \\
\text { against two } \\
\text { distinct epitopes of HER2 }\end{array}$ \\
\hline \multicolumn{2}{|c|}{ Antibody-Drug Conjugates (ADC) } \\
\hline SYD 985 & $\begin{array}{l}\text { Trastuzumab with an alkylant prodrug } \\
\text { DUBA (Duocarmicin derivate) } \\
\text { payload }\end{array}$ \\
\hline DS-8201 & $\begin{array}{l}\text { HER } 2 \text { antibody attached to } \\
\text { topoisomerase I inhibitor (DXd) } \\
\text { payload }\end{array}$ \\
\hline \multicolumn{2}{|c|}{ Tyrosine Kynase Inhibitors (TKIs) } \\
\hline Neratinib & $\begin{array}{l}\text { Oral TKI that irreversibly inhibits } \\
\text { HER1, HER2 and HER } 4\end{array}$ \\
\hline Tucatinib & $\begin{array}{l}\text { Oral TKI, ATP competitive, } \\
\text { selectively inhibits HER2 relative to } \\
\text { EGFR }\end{array}$ \\
\hline Poziotinib & $\begin{array}{l}\text { Irreversible oral TKI, pan-HER kinase } \\
\text { inhibitor }\end{array}$ \\
\hline Pyrotinib & $\begin{array}{l}\text { Irreversible oral, TKI pan-HER kinase } \\
\text { inhibitor }\end{array}$ \\
\hline \multicolumn{2}{|c|}{ Immune approaches } \\
\hline Atezolizumab & Anti-PD-L1 antibody \\
\hline $\begin{array}{l}\text { Pembrolizum } \\
\text { ab }\end{array}$ & Anti-PD-L1 antibody \\
\hline \multicolumn{2}{|c|}{ CDK4/6 inhibitor } \\
\hline Palbociclib & CDK4/6 inhibitor \\
\hline Abemaciclib & CDK4/6 inhibitor \\
\hline Ribociclib & CDK4/6 inhibitor \\
\hline \multicolumn{2}{|c|}{ PI3K inhibitors } \\
\hline Alpelisib & $\alpha$-specific PI3K inhibitor \\
\hline Copanlisib & Pan-class PI3K inhibitor \\
\hline Taselisib & $\beta$-sparring PI3K inhibitor \\
\hline $\begin{array}{l}\text { ADCC. Antibody } \\
\text { Clinical benefit ra } \\
\text { reported, DCR. D } \\
\text { Inhibitor. T. Trast } \\
\text { PI3K. Phosphatid }\end{array}$ & $\begin{array}{l}\text { dependent cell-mediated cytotoxicity, CBR. } \\
\text { e, ORR. Overall response rate, NR. Not } \\
\text { sease control rate, TKI. Tyrosine Kynase } \\
\text { lzumab. CDK. Cyclin dependent kinase, } \\
\text { linositol-3-kinase. }\end{array}$ \\
\hline
\end{tabular}

Persephone was a randomized phase III non-inferiority trial comparing 6 months of trastuzumab to the standard 12 months in 4,088 patients enrolled from 152 sites in the
United Kingdom between 2007 and 2015. ${ }^{68,69}$ Patients received standard chemotherapy regimens as per institutional practice as either adjuvant chemotherapy or neoadjuvant chemotherapy, and either concurrently with or sequentially to trastuzumab, and trastuzumab for either 6 or 12 months based on random allocation. Randomization occurred before the 10th cycle of trastuzumab. At a median follow-up of 5 years, the researchers found near-identical results between the 2 treatment arms: DFS was $89.4 \%$ among women in the 6month arm and $89.8 \%$ among women in the 12-month arm. ${ }^{68,69}$

\section{Seven-year follow-up analysis of adjuvant Paclitaxel and Trastuzumab trial}

The first report from the adjuvant Paclitaxel and Trastuzumab trial, after a median follow-up of 4 years, showed a 3-year invasive DFS of $98.7 \%$. A secondary analysis was planned to report longer-term outcomes and characterize the biology of small HER2-positive tumors and genetic factors that may predispose to paclitaxelinduced peripheral neuropathy (TIPN) ${ }^{70}$ In this phase II study, patients with HER2-positive BC with tumors $3 \mathrm{~cm}$ or smaller and negative nodes received paclitaxel (80 $\mathrm{mg} / \mathrm{m} 2$ ) with trastuzumab for 12 weeks, followed by trastuzumab for 9 months. ${ }^{70}$ The primary endpoint was DFS. Recurrence-free interval (RFI), breast cancerspecific survival, and overall survival (OS) were also analyzed, 410 patients were enrolled from October 2007 to September 2010. The 7-year DFS of $93.3 \%$ included $94.6 \%$ in patients with HR-positive tumors and $90.7 \%$ in the HR-negative subgroup. Key secondary outcomes at 7 years included: relapse-free interval: $97.5 \%$, Breast cancer-specific survival: $98.6 \%$, OS: $95 .^{70}$ This long-term data support the use of adjuvant paclitaxel and trastuzumab as a treatment option for patients with stage I, HER 2positive breast cancer. This regimen represents an important step forward in de-escalating therapy to preserve the quality of life while achieving excellent outcomes for patients with HER2-positive breast cancer. ${ }^{70}$

\section{Adjuvant ado-Trastuzumab Emtansine versus Trastuzumab in early-stage HER2-Positive breast cancer}

The phase III KATHERINE clinical trial compared the use of ado-trastuzumab emtansine (T-DM1) vs trastuzumab as adjuvant therapy in patients with HER2-positive earlystage $\mathrm{BC}$ with residual invasive disease after receiving neoadjuvant chemotherapy and trastuzumab. ${ }^{43} 1,486$ patients from 273 sites in 28 countries were randomly assigned between April 2013 and December 2015 to receive adjuvant T-DM1 $3.6 \mathrm{mg} / \mathrm{kg}$ intravenously (IV) every 3 weeks $(n=743)$ or trastuzumab $6 \mathrm{mg} / \mathrm{kg}$ IV every 3 weeks $(n=743)$ for 14 cycles. T-DM1 reduced the risk of developing an invasive recurrence of the BC or death by $50 \%$, corresponding to an absolute improvement of 3-year invasive disease-free survival rate by 11.3 percentage points (77\% with trastuzumab and $88.3 \%$ with T-DM1). ${ }^{43}$ Secondary efficacy endpoints of disease-free survival and 
distant recurrence-free interval also demonstrated clinically meaningful improvements with T-DMI. ${ }^{43}$

\section{Extended duration of anti-HER2 therapy}

Food and Drug Administration (FDA) approved neratinib in 2017 for the extended adjuvant treatment of adult patients with early-stage HER $2+$ breast cancer, to follow adjuvant trastuzumab. ${ }^{71}$ Till now, the overall strategy has escalated the treatment by combining more HER 2 targeted agents. But, the treatment escalation is encumbered by high cost and significant toxicity, and in some cases might be an overtreatment. Thus, redesigning the current treatment strategies is crucial and de-escalation is a research priority to diminish adverse effects without compromising patient outcomes.

\section{CHALLENGES AND FUTURE DIRECTIONS}

\section{Targeting HER2/ER crosstalk}

Although HER2 inhibition is highly effective in improving outcomes in HER2-positive BC patients, but tumors expressing estrogen receptor (ER) have poorer responses to targeted therapy and are more likely to relapse. ${ }^{33,72,73}$ Current theories have revealed that a key mechanism of trastuzumab resistance in patients with HER2positive/ER-positive tumors could be crosstalk between HER2 and ER, most likely via PI3K. Significant crosstalk exists between the HER2 and ER pathways. It has been observed in preclinical studies with HER2-positive/ERpositive tumor models, that inhibition of HER2 results in an increase in ER signaling. ${ }^{74}$

PI3K is a main member of the HER2 signaling pathway. It plays a very important role in regulating ER expression in BC. A suggested solution to the issue of HER2/ER crosstalk is to combine HER2 inhibition with ER inhibition, blocking both mechanisms. Pre-clinical studies have found that this strategy is effective for ER-positive tumors with PIK3CA mutations, where coadministration of PI3K inhibitors with hormone therapy increased responses. ${ }^{75}$ In a few studies, the combination of HER2 and ER inhibition improved outcomes over inhibition of either pathway alone. ${ }^{76-78}$ In the neoadjuvant setting, targeting both pathways simultaneously did not impact on response. $^{79}$

\section{CONCLUSION}

Breast cancer is a very common, complex and heterogeneous disease. Highly malignant with poor metastasis and recurrence outcomes, HER2-positive BC accounts for $20-25 \%$ of all BC. Anti-HER2 therapy is the keystone for early and advanced HER2-positive BC.

Trastuzumab is a breakthrough drug for anti-HER2 treatment. One-year treatment with trastuzumab is a standard for adjuvant therapy. Pertuzumab also showed an overall good efficacy in adjuvant therapy. Double-targeted adjuvant therapy can be beneficial in high-recurrence risk groups (positive-lymph nodes or ER/PR negative patients). At present, the standard of first-line care for HER2-positive MBC is dual anti-HER2 blocking with pertuzumab and trastuzumab plus chemotherapy. The T-DM1 is recommended as the second-line treatment and smallmolecule TKI as the third-line.

Though trastuzumab, pertuzumab, lapatinib, and neratinib are greatly promising drugs, some patients may show no response or develop drug resistance after a period of treatment. There are several new Anti-HER2 agents and combination studies in clinical development. With the introduction of any new therapy or regimen, careful attention must be given to the risks versus benefits of therapy.

\section{Funding: No funding sources \\ Conflict of interest: None declared \\ Ethical approval: Not required}

\section{REFERENCES}

1. Cancer Fact Sheet. https://www.who.int/healthtopics/cancer\#tab=tab_1. Last accessed on 21st December, 2019.

2. Bray F, Ferlay J, Soerjomataram I, Siegel RL, Torre LA, Jemal A. Global cancer statistics 2018: GLOBOCAN estimates of incidence and mortality worldwide for 36 cancers in 185 countries. CA Cancer J Clin. 2018;68:394-424.

3. Breast cancer. https://www.who.int/cancer/prevention/diagnosisscreening/breast-cancer/en/. Last accessed on $21 \mathrm{st}$ December, 2019.

4. Malvia S, Bagadi SA, Dubey US, Saxena S. Epidemiology of breast cancer in Indian women. Asia Pac J Clin Oncol. 2017;13:289-295.

5. Mahtani R, Hineman L. Advances in HER2-Positive Breast Cancer: Novel Therapies and Adverse Event Management. J Adv Pract Oncol. 2019;10:136-153.

6. Burstein HJ. The distinctive nature of HER2-positive breast cancers. N Engl J Med. 2005;353:1652-4.

7. Figueroa-Magalhães MC, Jelovac D, Connolly R, Wolff AC. Treatment of HER2-positive Breast Cancer. Breast. 2014;23:128-136.

8. Baselga J, Coleman RE, Cortés J, Janni W. Advances in the management of HER2-positive early breast cancer. Crit Rev Oncol Hematol. 2017;119:113-122.

9. Zurawska U, Baribeau DA, Giilck S, Victor C, Gandhi S, Florescu A, et al. Outcomes of HER2-positive early-stage breast cancer in the trastuzumab era: a population-based study of Canadian patients.Curr Oncol. 2013;20:e539-45.

10. Ahmed S, Sami A, Xiang J. HER2-directed therapy: current treatment options for HER2-positive breast cancer. Breast Cancer. 2015;22:101-16.

11. Pernas S, Tolaney SM. HER2-positive breast cancer: new therapeutic frontiers and overcoming resistance. Ther Adv Med Oncol. 2019;11:1758835919833519. 
12. Pondé N, Brandão M, El-Hachem G, Werbrouck E, Piccart M. Treatment of advanced HER2-positive breast cancer: 2018 and beyond. Cancer Treat Rev. 2018;67:10-20.

13. Wuerstlein R, Harbeck N. Neoadjuvant Therapy for HER2-positive Breast Cancer. Rev Recent Clin Trials. 2017;12:81-92.

14. Sharp A, Johnston SR. Dose-reduced trastuzumab emtansine: active and safe in acute hepatic dysfunction. Case Rep Oncol. 2015;8:113-21.

15. Larionov AA. Current Therapies for Human Epidermal Growth Factor Receptor 2-Positive Metastatic Breast Cancer Patients. Front Oncol. 2018;8:89.

16. Lv Q, Meng Z, Yu Y, Jiang F, Guan D, Liang C et al. Molecular Mechanisms and Translational Therapies for Human Epidermal Receptor 2 Positive Breast Cancer. Int J Mol Sci. 2016;17:2095.

17. Rexer BN, Arteaga CL. Intrinsic and acquired resistance to HER2-targeted therapies in HER2 geneamplified breast cancer: mechanisms and clinical implications. Crit Rev Oncog. 2012;17:1-16.

18. Meric-Bernstam F, Johnson AM, Dumbrava EEI, Raghav K, Balaji K, Bhatt M, et al. Advances in HER2-Targeted Therapy: Novel Agents and Opportunities Beyond Breast and Gastric Cancer. Clin Cancer Res. 2019;25:2033-41.

19. Brufsky AM. Current Approaches and Emerging Directions in HER2-resistant Breast Cancer. Breast Cancer (Auckl). 2014;8:109-18.

20. Baselga J. A new anti-ErbB2 strategy in the treatment of cancer: prevention of ligand-dependent ErbB2 receptor heterodimerization. Cancer Cell. 2002;2:935.

21. Tzahar E, Waterman H, Chen X, Levkowitz G, Karunagaran D, Lavi S, et al. A hierarchical network of interreceptor interactions determines signal transduction by Neu differentiation factor/neuregulin and epidermal growth factor. Mol Cell Biol 1996;16:5276-87.

22. Lee-Hoeflich ST, Crocker L, Yao E, Pham T, Munroe $\mathrm{X}$, HoeflichKP, et al. A central role for HER3 in HER2-amplified breast cancer: implications for targeted therapy. Cancer Res. 2008;68:5878-87.

23. Menendez JA, Schroeder B, Peirce SK, Vellon L, Papadimitropoulou A, Espinoza I, et al. Blockade of a key region in the extracellular domain inhibits HER2 dimerization and signaling. $\mathbf{J}$ Natl Cancer Inst. 2015;107:djv090.

24. Franklin MC, Carey KD, Vajdos FF, Leahy DJ, de Vos AM, Sliwkowski MX. Insights into ErbB signaling from the structure of the ErbB2-pertuzumab complex. Cancer Cell. 2004;5:317-28.

25. Baselga J, Cortés J, Kim SB, Im SA, Hegg R, ImYH, et al. CLEOPATRA Study Group. Pertuzumab plus trastuzumab plus docetaxel for metastatic breast cancer. N Engl J Med. 2012;366:109-19.

26. Swain SM, Baselga J, Kim SB, Ro J, Semiglazov V, Campone $\mathrm{M}$ et al. CLEOPATRA Study Group. Pertuzumab, trastuzumab, and docetaxel in HER2- positive metastatic breast cancer. $\mathrm{N}$ Engl $\mathrm{J}$ Med 2015;372:724-34

27. Baselga J, Bradbury I, Eidtmann H, Di Cosimo S, de Azambuja E, Aura C, et al. Lapatinib with trastuzumab for HER2-positive early breast cancer (NeoALTTO): a randomized, open-label, multicenter, phase 3 trial. Lancet. 2012b;379:633-40.

28. Blackwell KL, Burstein HJ, Storniolo AM, Rugo HS, Sledge G, Aktan G, et al. Overall survival benefit with lapatinib in combination with trastuzumab for patients with human epidermal growth factor receptor 2positive metastatic breast cancer: final results from the EGF104900. J Clin Oncol. 2012;30:2585-92.

29. Bose R, Kavuri SM, Searleman AC, Shen W, Shen D, Koboldt DC, et al. Activating HER2 mutations in HER2 gene amplification negative breast cancer. Cancer Discov. 2013;3:224-37.

30. Rabindran SK, Discafani CM, Rosfjord EC, Baxter M, Floyd MB, Golas J, et al. Antitumor activity of HKI272, an orally active, irreversible inhibitor of the HER2 tyrosine kinase. Cancer Res. 2004;64:39583965.

31. Sánchez-Martín M, Pandiella A. Differential action of small molecule HER kinase inhibitors on receptor heterodimerization: therapeutic implications. Int $\mathbf{J}$ Cancer. 2012;131:244-252.

32. Piccart-Gebhart MJ, Procter M, Leyland-Jones B, Goldhirsch A, Untch M, Smith I, et al.; Herceptin Adjuvant (HERA) Trial Study Team. Trastuzumab after adjuvant chemotherapy in HER2 positive breast cancer. N Engl J Med 2005;353:1659-1672.

33. Cameron D, Piccart-Gebhart MJ, Gelber RD, Procter M, Goldhirsch A, de Azambuja E, et al, Herceptin Adjuvant (HERA) Trial Study Team. 11 years' followup of trastuzumab after adjuvant chemotherapy in HER2-positive early breast cancer: final analysis of the HERceptin Adjuvant (HERA) trial. Lancet. 2017;389:1195-1205.

34. Perez EA, Romond EH, Suman VJ, Jeong JH, Sledge $\mathrm{G}$, Geyer CE Jr, et al. Trastuzumab plus adjuvant chemotherapy for human epidermal growth factor receptor 2-positive breast cancer: planned joint analysis of overall survival from NSABP B-31 and NCCTG N9831. J Clin Oncol. 2014;32:3744-52.

35. Gianni L, Eiermann W, Semiglazov V, Lluch A, Tjulandin S, Zambetti M, et al. Neoadjuvant and adjuvant trastuzumab in patients with HER2-positive locally advanced breast cancer (NOAH): follow-up of a randomised controlled superiority trial with a parallel HER2-negative cohort. Lancet Oncol. 2014;15:640-7.

36. Goss PE, Smith IE, O’Shaughnessy J, Ejlertsen B, Kaufmann M, Boyle F, et al. Adjuvant lapatinib for women with early-stage HER2-positive breast cancer: a randomized, controlled, phase 3 trial. Lancet Oncol. 2013;14:88-96.

37. Piccart-Gebhart M, Holmes E, Baselga J, de Azambuja E, Dueck AC, Viale G, et al. Adjuvant Lapatinib and Trastuzumab for Early Human Epidermal Growth Factor Receptor 2-Positive Breast 
Cancer: Results From the Randomized Phase III Adjuvant Lapatinib and/or Trastuzumab Treatment Optimization Trial. J Clin Oncol. 2016;34:1034-42.

38. Moreno-Aspitia A, Holmes E, Jackisch C, de Azambuja E, Boyle F, Hillman DW, et al. Updated results from the phase III ALTTO trial (BIG NCCTG/Alliance N063D) comparing one year of antiHER2 therapy with lapatinib alone (L), trastuzumab alone $(\mathrm{T})$, their sequence $(\mathrm{T} \rightarrow \mathrm{L})$ or their combination $(\mathrm{L}+\mathrm{T})$ in the adjuvant treatment of HER2-positive early breast cance. J Clin Oncol. 2017;35(suppl):2-06.

39. Chan A, Delaloge S, Holmes FA, Moy B, Iwata H, Harvey VJ et al. ExteNET Study Group. Neratinib after trastuzumab-based adjuvant therapy in patients with HER2-positive breast cancer (ExteNET): a multicentre, randomised, double-blind, placebocontrolled, phase 3 trial. Lancet Oncol. 2016;17:36777.

40. Martin M, Holmes FA, Ejlertsen B, Delaloge S, Moy $B$, Iwata $\mathrm{H}$, et al. Neratinib after trastuzumab-based adjuvant therapy in early-stage HER2-positive breast cancer: 5-year analysis of the phase III ExteNET trial. Ann Oncol. 2017;28(5).

41. von Minckwitz G, Procter M, de Azambuja E, Zardavas D, Benyunes M, Viale G et al. APHINITY Steering Committee and Investigators. Adjuvant pertuzumab and trastuzumab in early HER2-positive breast cancer. N Engl J Med. 2017;377:122-31.

42. Lambert JM, Chari RV. Ado-trastuzumab Emtansine (T-DM1): an antibody-drug conjugate (ADC) for HER2-positive breast cancer. J Med Chem. 2014;57:6949-64.

43. von Minckwitz G, Huang CS, Mano MS, Loibl S, Mamounas EP, Untch $M$ et al. KATHERINE Investigators. Trastuzumab Emtansine for Residual Invasive HER2-Positive Breast Cancer. N Engl J Med. 2019;380:617-628.

44. Madarnas Y, Trudeau M, Franek JA, McCready D, Pritchard KI, Messersmith H. Adjuvant/neoadjuvant trastuzumab therapy in women with HER-2/neuoverexpressing breast cancer: a systematic review. Cancer Treat Rev. 2008;34:539-57.

45. Arnould L, Arveux P, Couturier J, Gelly-Marty M, Loustalot C, Ettore F et al. Pathologic complete response to trastuzumab-based neoadjuvant therapy is related to the level of HER-2 amplification. Clin Cancer Res. 2007;13:6404-9.

46. Buzdar AU, Ibrahim NK, Francis D, Booser DJ, Thomas ES, Theriault RL et al. Significantly higher pathologic complete remission rate after neoadjuvant therapy with trastuzumab, paclitaxel, and epirubicin chemotherapy: results of a randomized trial in human epidermal growth factor receptor 2-positive operable breast cancer. J Clin Oncol. 2005;23:3676-3685.

47. Gianni L, Eiermann W, Semiglazov V, Manikhas A, Lluch A, Tjulandin S, et al. Neoadjuvant chemotherapy with trastuzumab followed by adjuvant trastuzumab versus neoadjuvant chemotherapy alone, in patients with HER2-positive locally advanced breast cancer (the NOAH trial): a randomised controlled superiority trial with a parallel HER2negative cohort. Lancet. 2010;375:377-84.

48. Untch M, Fasching PA, Konecny GE, Hasmüller S, Lebeau A, Kreienberg R et al. Pathologic complete response after neoadjuvant chemotherapy plus trastuzumab predicts favorable survival in human epidermal growth factor receptor 2-overexpressing breast cancer: results from the TECHNO trial of the AGO and GBG study groups. J Clin Oncol. 2011;29:3351-7.

49. Buzdar AU, Suman VJ, Meric-Bernstam F, Leitch AM, Ellis MJ, Boughey JC et al. Fluorouracil, epirubicin, and cyclophosphamide (FEC-75) followed by paclitaxel plus trastuzumab versus paclitaxel plus trastuzumab followed by FEC-75 plus trastuzumab as neoadjuvant treatment for patients with HER2positive breast cancer (Z1041): a randomised, controlled, phase 3 trial. Lancet Oncol. 2013;14:131725.

50. Untch M, Rezai M, Loibl S, Fasching PA, Huober J, Tesch $\mathrm{H}$ et al. Neoadjuvant treatment with trastuzumab in HER2-positive breast cancer: results from the GeparQuattro study. J Clin Oncol. 2010;28:2024-31.

51. Ismael G, Hegg R, Muehlbauer S, Heinzmann D, Lum B, Kim SB. et al. Subcutaneous versus intravenous administration of (neo) adjuvant trastuzumab in patients with HER2-positive, clinical stage I-III breast cancer (HannaH study): a phase 3, open-label, multicentre, randomised trial. Lancet Oncol. 2012;13:869-78.

52. Untch M, Loibl S, Bischoff J, Eidtmann H, Kaufmann M, Blohmer JU et al. Lapatinib versus trastuzumab in combination with neoadjuvant anthracycline-taxanebased chemotherapy (GeparQuinto, GBG 44): a randomised phase 3 trial. Lancet Oncol. 2012;13:13544.

53. Robidoux A, Tang G, Rastogi P, Geyer CE Jr, Azar CA, Atkins JN, et al. Lapatinib as a component of neoadjuvant therapy for HER2-positive operable breast cancer (NSABP protocol B-41): an open-label, randomised phase 3 trial. Lancet Oncol. 2013;14:1183-92.

54. Gianni L, Pienkowski T, ImYH, Roman L, Tseng LM, Liu MC et al. Efficacy and safety of neoadjuvant pertuzumab and trastuzumab in women with locally advanced, inflammatory, or early HER2-positive breast cancer (NeoSphere): a randomisedmulticentre, open-label, phase 2 trial. Lancet Oncol. 2012;13:2532.

55. Gianni L, Pienkowski T, ImYH, Tseng LM, Liu MC, Lluch A, et al. 5-year analysis of neoadjuvant pertuzumab and trastuzumab in patients with locally advanced, inflammatory, or early-stage HER2positive breast cancer (NeoSphere): a multicentre, open-label, phase 2 randomised trial. Lancet Oncol. 2016;17:791-800.

56. Schneeweiss A, Chia S, Hickish T, Harvey V, Eniu A, Hegg $\mathrm{R}$ et al. Pertuzumab plus trastuzumab in combination with standard neoadjuvant anthracycline- 
containing and anthracycline-free chemotherapy regimens in patients with HER2-positive early breast cancer: a randomized phase II cardiac safety study (TRYPHAENA). Ann Oncol. 2013;24:2278-84.

57. Trail PA, Dubowchik GM, Lowinger TB. Antibody drug conjugates for treatment of breast cancer: Novel targets and diverse approaches in ADC design. Pharmacol Ther. 2018;181:126-42.

58. Verma S, Miles D, Gianni L, Krop IE, Welslau M, Baselga $\mathbf{J}$ et al. Trastuzumab emtansine for HER2 positive advanced breast cancer. $\mathrm{N}$ Engl J Med. 2012;367:1783-1791.

59. Iwata H, Tamura K, Doi T, Tsurutani J, Modi S, Park $\mathrm{H}$ et al. Trastuzumab deruxtecan (DS-8201a) in subjects with HER2-expressing solid tumors: longterm results of a large phase 1 study with multiple expansion cohorts. J Clin Oncol. 2018;36:2501.

60. Saura C, Thistlethwaite F, Banerji U, Lord S, Moreno $\mathrm{V}$, MacPherson I, et al. A phase I expansion cohorts study of SYD985 in heavily pretreated patients with HER2-positive or HER2-low metastatic breast cancer [abstract]. J Clin Oncol. 2018;36:1014.

61. Yurkovetskiy A, Gumerov D, Ter-Ovanesyan E, Conlon P, Devit $\mathrm{M}$, Bu C, et al. Non-clinical pharmacokinetics of XMT-1522, a HER2 targeting auristatin-based antibody drug conjugate [abstract]. Proc Am Assoc Cancer Res Annual Meeting 2017. Cancer Res. 2017;77(13):48.

62. Escrivá-de-Romaní S, Arumí M, Bellet M, Saura C. HER2-positive breast cancer: Current and new therapeutic strategies. Breast. 2018;39:80-88.

63. Esposito A, Viale G, Criscitiello C, Curigliano G. A clinical perspective on escalating or de-escalating adjuvant therapy in HER2+ breast cancer. Expert Rev Clin Pharmacol. 2019;12:9-16.

64. Joensuu H, Bono P, Kataja V, Alanko T, Kokko R, Asola R, et al. Fluorouracil, epirubicin, and cyclophosphamide with either docetaxel or vinorelbine, with or without trastuzumab, as adjuvant treatments of breast cancer: final results of the FinHer Trial. J Clin Oncol. 2009;27:5685-5692.

65. Slamon D, Eiermann W, Robert N, Pienkowski T, Martin M, Press $M$ et al. Adjuvant trastuzumab in HER2-positive breast cancer. $N$ Engl J Med. 2011;365:1273-1283.

66. Guarneri V, Frassoldati A, Bruzzi P, D'Amico R, Belfiglio M, Molino A. Multicentric, randomized phase III trial of two different adjuvant chemotherapy regimens plus three versus twelve months of trastuzumab in patients with HER2- positive breast cancer (Short-HER Trial; NCT00629278). Clin Breast Cancer. 2008;8:453-6.

67. Conte PF, Bisagni G, Frassoldati A, Brandes AA, Anselmi E, Giotta F et al. 9 weeks vs 1 year adjuvant trastuzumab in combination with chemotherapy: results of the phase III multicentric Italian study ShortHER [abstract]. J Clin Oncol. 2017;35:501.

68. Earl HM, Cameron DA, Miles D, Wardley AM, Ogburn E, Vallier AL et al. The PERSEPHONE trial: Duration of Trastuzumab with Chemotherapy in women with HER-2 positive early breast cancer[abstract]. J Clin Oncol. 2012;30:660.

69. Earl HM, Hiller L, Vallier AL, Loi S, McAdam K, Hughes-Davies L et al. 6 versus 12 months of adjuvant trastuzumab for HER2-positive early breast cancer (PERSEPHONE): 4-year disease-free survival results of a randomised phase 3 non-inferiority trial. Lancet. 2019;393:2599-612.

70. Tolaney S, Guo H, Pernas S, Barry W, Dillon D, Ritterhouse L, et al. Seven-Year Follow-Up Analysis of Adjuvant Paclitaxel and Trastuzumab Trial for Node-Negative, Human Epidermal Growth Factor Receptor 2-Positive Breast Cancer. Journal of Clinical Oncology. 2019;37(22):1868-75.

71. U.S. Food \& Drugs Administration, Prescribing Information for Nerlynx. http://www.accessdata.fda.gov/drugsatfda_docs/label /2017/208051s000lbl.pdf. Last accessed on 30th December, 2019.

72. André F, O'Regan R, Ozguroglu M, Toi M, Xu B, Jerusalem $G$, et al. Everolimus for women with trastuzumab-resistant, HER2-positive, advanced breast cancer (BOLERO-3): a randomised, doubleblind, placebo-controlled phase 3 trial. Lancet Oncol. 2014;15:580-91.

73. De Laurentiis M, Arpino G, Massarelli E, Ruggiero A, Carlomagno C, Ciardiello F et al. A meta-analysis on the interaction between HER-2 expression and response to endocrine treatment in advanced breast cancer. Clin Cancer Res. 2005;11:4741-8.

74. Xia W, Bacus S, Hegde P, Husain I, Strum J, Liu L et al. A model of acquired autoresistance to a potent ErbB2 tyrosine kinase inhibitor and a therapeutic strategy to prevent its onset in breast cancer. Proc Natl Acad Sci U S A. 2006;103:7795-800.

75. Bosch A, Li Z, Bergamaschi A, Ellis H, Toska E, Prat A et al. PI3K inhibition results in enhanced estrogen receptor function and dependence in hormone receptor-positive breast cancer.Sci Transl Med. 2015;7:283ra51.

76. Johnston S, Pippen J Jr, Pivot X, Lichinitser M, Sadeghi S, Dieras V et al. Lapatinib combined with letrozole versus letrozole and placebo as first-line therapy for postmenopausal hormone receptorpositive metastatic breast cancer. J Clin Oncol. 2009;27:5538-46.

77. Kaufman B, Mackey JR, Clemens MR, Bapsy PP, Vaid A, Wardley A et al. Trastuzumab plus anastrozole versus anastrozole alone for the treatment of postmenopausal women with human epidermal growth factor receptor 2-positive, hormone receptorpositive metastatic breast cancer: results from the randomized phase III TAnDEM study. J Clin Oncol. 2009;27:5529-37.

78. Rimawi MF, Mayer IA, Forero A, Nanda R, Goetz MP, Rodriguez AA et al. Multicenter phase II study of neoadjuvant lapatinib and trastuzumab with hormonal therapy and without chemotherapy in patients with human epidermal growth factor receptor 2- 
overexpressing breast cancer: TBCRC 006. J Clin Oncol. 2013;31:1726-31.

79. Nitz UA, Gluz O, Christgen M, Grischke EM, Augustin D, Kuemmel S et al; West-German Study Group (WSG)-ADAPT Investigators. De-escalation strategies in HER2-positive early breast cancer (EBC): final analysis of the WSG-ADAPT HER2+/HRphases II trial: efficacy, safety, and predictive markers for 12 weeks of neoadjuvant dual blockade with trastuzumab and pertuzumab \pm weekly paclitaxel. Ann Oncol. 2017;28:2768-2772.

Cite this article as: Surti RP. Current treatment approaches for breast cancer patients with HER2positive disease in the adjuvant, and neo-adjuvant setting. Int J Basic Clin Pharmacol 2021;10:596-608. 